\title{
ASSESSMENT OF THE FREQUENCY AND RATIONALITY OF PRESCRIBED MEDICINES IN PATIENTS WITH LIVER CIRRHOSIS
}

\author{
Iryna Fediak \\ Department of Organization and Economics of Pharmacy and Drug Technology ${ }^{l}$ \\ irynafediak@gmail.com \\ Oleksandra Maksymenko \\ Department of Organization and Economics of Pharmacy and Drug Technology ${ }^{l}$ \\ olexandra.maksymenko@gmail.com \\ ${ }^{1}$ Ivano-Frankivsk National Medical University \\ 2 Halytska str., Ivano-Frankivsk, Ukraine, 76018
}

\begin{abstract}
The aim. Assessment of the dynamics of prescribing drugs to patients with liver cirrhosis (LC, K 74), in terms of real clinical practice by methods of clinical and economic analysis.

Materials and methods. 355 medical cards of inpatients with cirrhosis of the liver, which were divided into 4 groups depending on the period of stay of patients in the hospital. Methods: compatible retrospective $\mathrm{ABC}$-frequency analysis, which ranked drugs consumed by patients in real clinical practice, according to the frequency of appointment using $\mathrm{ABC}$-segmentation according to the Pareto principle (A - $80 \%$ of drugs appointments: $\mathrm{B}-15 \%$ : $\mathrm{C}-5 \%$ ); VEN-analysis, which divides the consumed drugs on a formal basis depending on the presence/absence of a particular drug in the regulations: vital (Vital or V), necessary (Essential or E) and secondary (Non-essential or N).

Results. Cirrhosis of the liver in recent years has been on the 10th - 11th place among the causes of death in the world. The analysis of prescribed drugs to patients with LC in real clinical practice in Ivano-Frankivsk region of Ukraine revealed that over the years doctors prescribed fewer drugs on average per patient (11.4 drugs $\rightarrow 8.8$ drugs), which can be considered a positive fact. Among the prescribed drugs, drugs of group A - «Drugs that affect the digestive system and metabolism» prevailed, the share of which increased and was the highest in 2019 - 2020 (2007-2009 - 44.6\%; 2012-2013-46.6 \%; 2015-2016-48.1\%; $2019-2020-48.55 \%)$; the share of dietary supplements also increased from $1.65 \%$ to $6.52 \%$.

Conclusions. Combined ABC-frequency and VEN-analyzes showed that the leaders in the years of hospital stay were the following drugs: Sodium chloride, Ademetionine, Pantoprazole, Spironolactone, Thioctic acid, Ornithine, Asparaginate K-Mg, Torasemide, Furosemide. However, the vital class V included only 9-11\% of drugs from the whole set of prescribed drugs, which requires systemic correction in accordance with European recommendations.
\end{abstract}

Keywords: liver cirrhosis; retrospective $\mathrm{ABC}$ frequency analysis; VEN analysis; real clinical practice.

DOI: $10.21303 / 2504-5679.2021 .001599$

\section{Introduction}

Chronic liver disease occurs worldwide regardless of age, gender, region or race. Liver cirrhosis (LC) is the final stage of chronic liver disease, characterized by fibrosis and transformation of the normal structure of the liver with the formation of regenerative nodules and can have a variety of clinical manifestations and complications [1].

In 2017, LC caused the deaths of more than 1.32 million people [1.27-1.45], of which 440.000 [416.000-518.000] women and 883.000 [838.000-967.000] men worldwide, compared with 899.000 [829.000 -948.000] deaths in 1990. Mortality from LC was $2.4 \%$ [2.3-2.6] of the total number of deaths in the world in 2017, compared with $1.9 \%$ [1.8-2.0] in 1990. At the national level, the standardized mortality rate from LC was the lowest in Singapore in 2017 (3.7 [3.3-4.0] per 100,000) and the highest in Egypt since 1990 (103.3 [64.4-133.4] per 100.000) [2]. According to the WHO, the standardized mortality rate due to LC per 100.000 population among women and men in 2016 in different countries was: the highest in Egypt - 121.6 and 200.4; the lowest in Fiji 0.8 and 1.6, respectively [3]. According to the latest WHO data published in 2018, mortality from liver disease in the world reached 1.247.237 and ranks 11th in the world ranking [4]. 
As LC remains one of the leading causes of death worldwide, clinical and economic evaluation of the pharmacotherapy consumed by patients with LC is relevant to optimize the provision of effective medical and pharmaceutical care.

The aim. Assessment of the dynamics of prescribed drugs to patients with liver cirrhosis (LC, K 74), in terms of real clinical practice by methods of clinical and economic analysis.

\section{Materials and methods}

The sample for the study consisted of 355 medical cards form No. 003/o inpatients with LC(K 74), which were obtained by random selection from the archives of gastroenterological departments of Municipal Non-Commercial Enterprises «Regional Clinical Hospital of Ivano-Frankivsk Regional Council» and «Ivano-Frankivsk Central City Clinical Hospital». These medical records were divided into 4 groups depending on the period of stay of patients in the hospital. Thus, the first group consisted of 56 medical cards of patients for 2007-2009, the second - 189 cards for 2012-2013, the third - 55 cards for 2015-2016andthe fourth-55 cards for2019-2020.Permits of chiefphysiciansofeach healthcareinstitution were obtained to work with archival materials while maintaining the secrecy of personal data of patients.

The following methods were used for the study: frequency method of clinical and economic research, which consisted of ranking the drugs consumed by frequency of use - in the whole set of purposes and among the names of drugs by international non-proprietary names (INN); compatible ABC-frequency method, which consisted in the distribution of prescribed drugs according to the Pareto principle (group $\mathrm{A}-80 \%$ of drug prescriptions, group $\mathrm{B}-15 \%$, and group $\mathrm{C}-5 \%$ ); VEN-analysis, which distributed the consumed drugs on a formal basis depending on the presence/absence of certain drugs in regulations (class V - required drugs (draft Unified Clinical Protocol of primary, secondary (specialized) tertiary (highly specialized) medical care «Liver cirrhosis and its complications», 2016, based on evidence-based medicine), class E - important drugs (Clinical protocol for medical care for patients with cirrhosis of the liver, approved by the order of the Ministry of Health of Ukraine No. 271 from 13.06.2005), group $\mathrm{N}$ - unimportant drugs, other drugs not included in classes V and E).

\section{Research results}

A retrospective clinical and economic study of prescriptions revealed that 641 patients with LC were prescribed 641 drugs by trade name, which averaged 11.4 drugs per patient; II group 1989 in total and 10.5 drugs in average; III group - 624 in total and 11.3 drugs in average; group IV - 484 in total and 8.8 drugs in average, respectively. A total of 121 names of drugs by INN for the first study group, 146 drugs by INN - for the second study group, 107 drugs by INN - for the third group and 88 drugs by INN - for the fourth group groups.

This analysis also revealed that patients of the first group were prescribed drugs belonging to the 9 ATC classification groups and 2 units of biologically active additives (dietary supplements) (Fig. 1, a), persons of the second group - drugs who belonged to the 11 ATC classification groups and 8 units of dietary supplements (Fig. 1, b), patients of the III group - drugs belonging to the 10 ATC classification groups and 6 units of dietary supplements (Fig. 1, c), and patients of the IV group - drugs belonging to the 9 ATC classification groups and 9 units of dietary supplements (DS) (Fig. 1, $\boldsymbol{d}$ ).

The data graphically shown in Fig. 1, illustrate that the leader among the ATC classification groups during all years was group A - CDrugs that affect the digestive system and metabolism, namely: $44.6 \%, 46.6 \%, 48.1 \%$ and $48.55 \%$ respectively. The second position is occupied by group $\mathrm{C}-$ «Drugs for the treatment of diseases of the cardiovascular system» for the I and II groups of $15.7 \%$ and $14.08 \%$, and for the III and IV - group B - «Means affecting the blood system and hematopoiesis» $11.4 \%$ and $13.4 \%$, respectively. The third place is also occupied by groups $\mathrm{B}$ and $\mathrm{C}$, but on the contrary: for the I and II groups - group B - $14.9 \%$ and $10.7 \%$, respectively, and for the III and IV - group C $-10.13 \%$ and $10.87 \%$, respectively.

Combined ABC-frequency analysis showed the following: in the first study group of medical records, group A, which provided $80 \%$ of drugs prescriptions, amounted to 38 drugs per INN, which was $31 \%$, group B - 51 drugs per INN (42\%), group C - 32 drugs for INN (27\%); in the second 30 drugs, 44 drugs, 72 drugs by INN (21 \%, $30 \%, 49 \%)$; in the third-27 drugs, 50 drugs, 31 drugs (25\%, $46 \%, 29 \%$ ); in the IV - 25 drugs, 38 drugs, 25 drugs (29\%, $43 \%, 28 \%$ ), respectively (Fig. 2). 


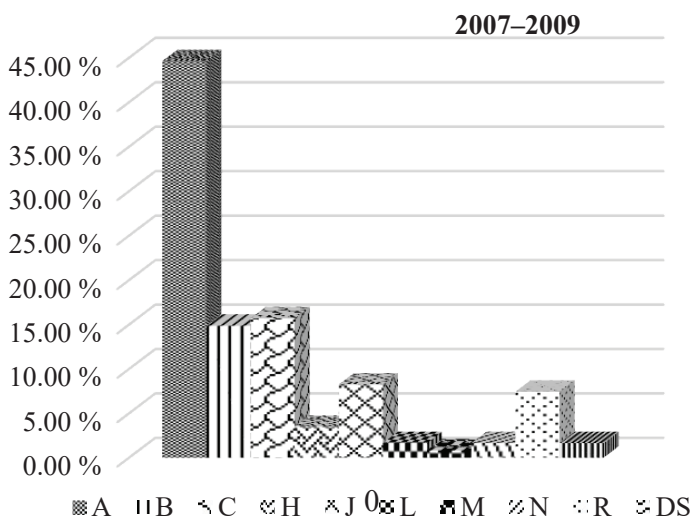

$a$

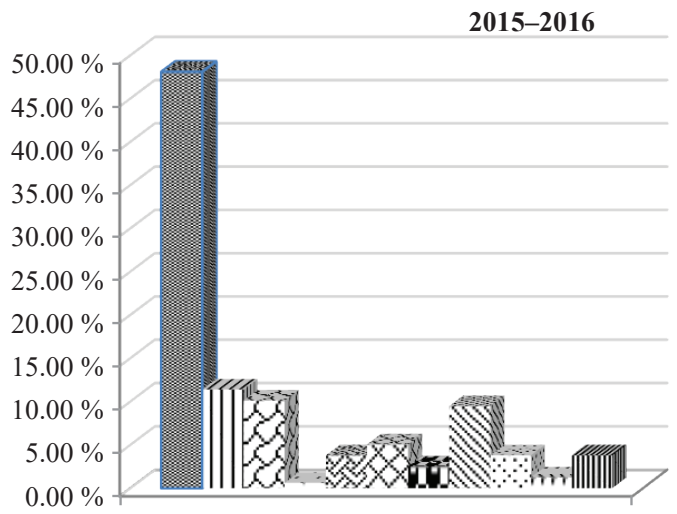

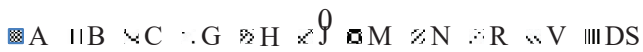

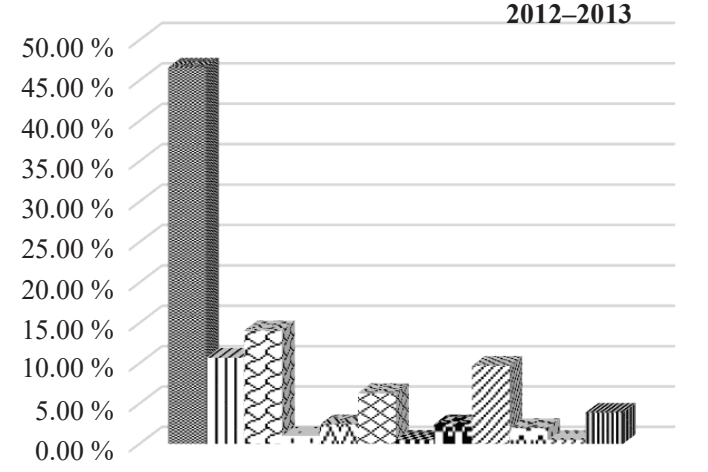

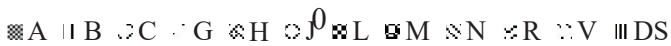
$b$

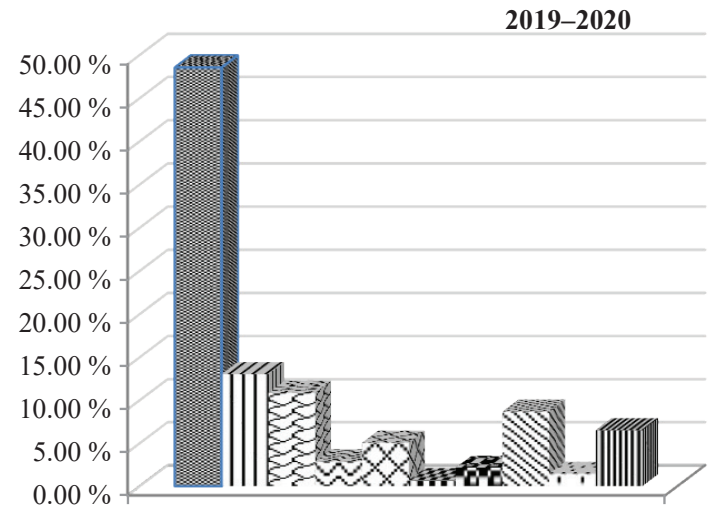

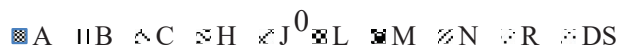
d

Fig. 1. The level of consumption of drugs by ATC classification groups according to the years of stay of patients in the hospital: $a-2007-2009 ; b-2012-2013$; $c-2015-2016 ; d-2019-2020$
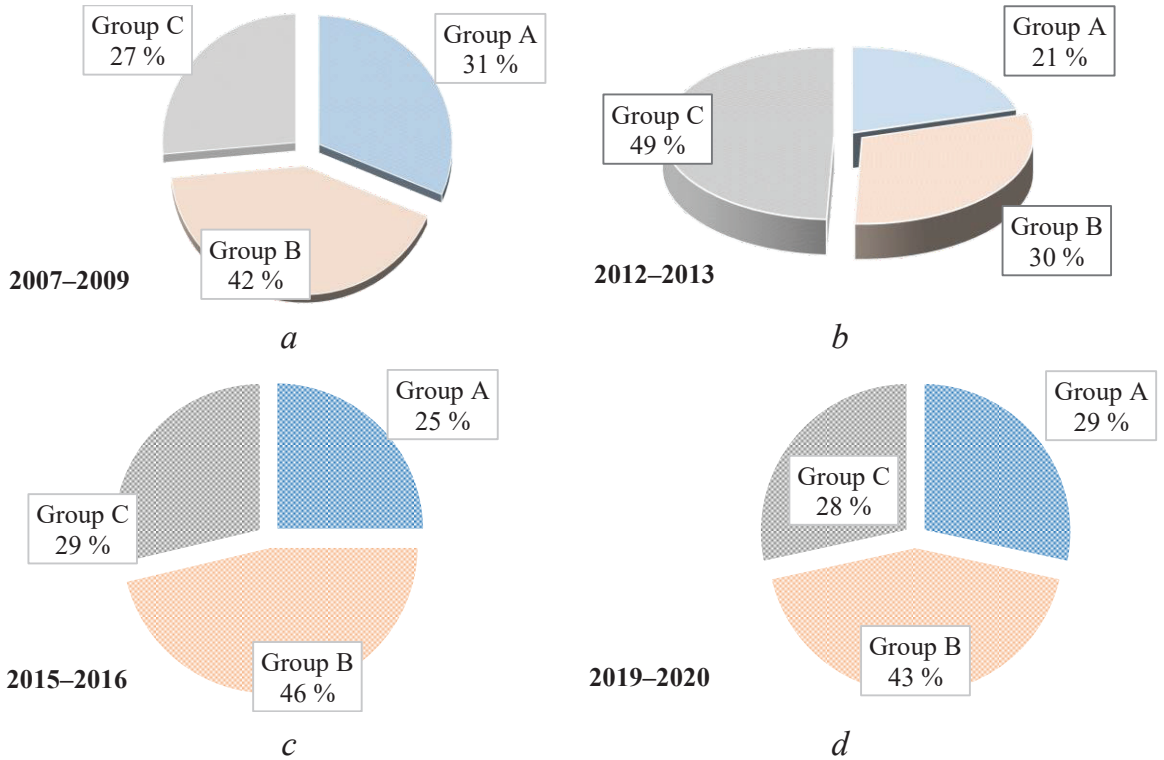

Fig. 2. Distribution of drugs by joint ABC-frequency analysis for the I-th $(a)$, II-th $(b)$, III-th $(c)$ and IV-th $(d)$ study groups in the dynamics of the years of appointment: $a-2007-2009 ; b-2012-2013 ; c-2015-2016 ; d-2019-2020$ 
The leaders in groups A by years of hospital stay were the following drugs: Sodium chloride, Ademetionine, Pantoprazole, Spironolactone, Thioctic acid, Ornithine, Asparaginate K-Mg, Phhospholipids, Torasemide, Furosemide.

The next stage of the study was a VEN-analysis of the pharmacotherapy consumed by patients in the relevant periods according to the INN. The distribution of drugs by classes of rationality is presented in Table $\mathbf{1 .}$

Table 1

The principle of distribution of drugs prescribed to patients with LC in real clinical practice, according to the classes of rationality

\begin{tabular}{ccc}
\hline V class & E class & N class \\
\hline
\end{tabular}

Diuretics (Spironolactone, Furosemide)

Other diuretics

Antimicrobial drugs (Amoxicillin + Clavulonic acid, Hemiflo- Other antibacterial drugs

xacin, Levofloxacin, Metronidazole, Moxifloxacin, Norfloxacin, Other antiviral drugs

Ofloxacin, Pefloxacin, Cefotaxime, Ciprofloxacin, Ceftriaxone, Ciprofloxacin)

Plant hepatoprotectors

Antiviral drugs (Pegylated Interferon alpha, Ribavirin, Simepre- Phospholipids preparations

vir, Sofosbuvir, Sofosbuvir + Ladyspace, Ombitasvir/Paritraver/ Metabolic hepatoprotectors

Ritonavir, Dasabuver)

Ursodeoxycholic acid preparations

Enzymes
All other drugs that have been used to treat the study groups of patients with LC

Preparations of hormones of the posterior pituitary gland: (Terli- Preparations of calcium and fat-sopressin) luble vitamins A, E, D, K.

Drugs of different pharmacotherapeutic groups for the treatment Drugs for infusion therapy of LC (L-Ornithine-L-Aspartate, Lactulose, Rifaximin, Silymarin)

Beta-blockers (Carvedilol, Propranolol)

Other amino acid preparations

Blood substitutes and protein fractions of blood plasma (Albumin) Prebiotics

In Fig. 3 graphically shows the percentage of drugs in each class $\mathrm{V}, \mathrm{E}$ and $\mathrm{N}$ for the respective periods.

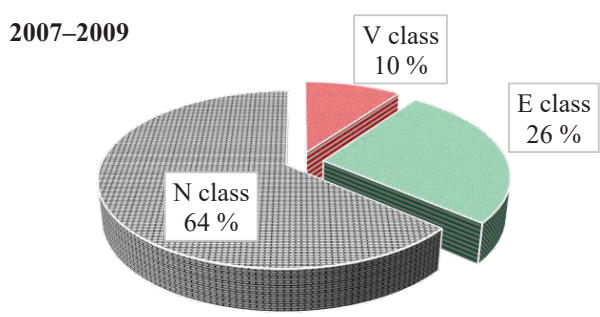

$a$

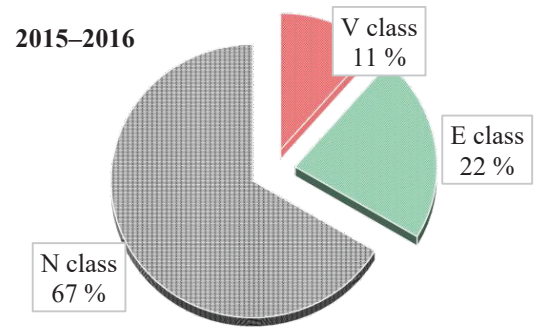

c

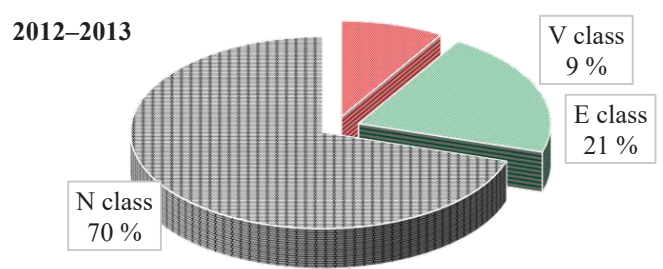

$b$

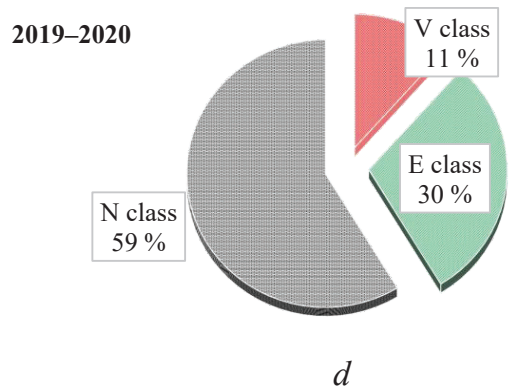

Fig. 3. Distribution of drugs by VEN-analysis for the 1st (a), II (b), III (c) and IV (d) groups of the studied groups in the dynamics of the years of appointment: $a-2007-2009 ; b-2012-2013$; $c-2015-2016 ; d-2019-2020$ 
Table 2 shows the TOP-20 drugs by INN by frequency of use for the treatment of patients with LC for the study groups. The absolute leader in prescriptions in each group of studied medical records of patients with LC was a universal solvent - isotonic solution of Sodium chloride, which was used as a basis for infusion therapy (Ademetionine, Ornithine, Arginine). The top three drugs - Ademetionine, Pantoprazole, Spironolactone - remained unchanged during the last 2 study periods - in 2019-2020 and 2015-2016.

And according to VEN-segmentation in TOP-20 drugs during the years of research from the proposed class V there were only 4 drugs by INN, namely: Spironolactone, which took 1st place in the ranking of appointments in 2015-2016, 2nd - during 2012-2013 and 2007-2009, 3rd 2019-2020; Ornithine, which was 5thin the ranking in 2015-2016, 6th in 2019-2020, 12th in 2012-2013 and was absent among prescribed drugs in 2007-2009; Furosemide, which was more often prescribed in 2007-2009 (5th in the ranking), in 2012-2013 and in 2015-2016 it was 9th, and in 2019-2020 - 12th; Albumin, which rose in the rankings in recent years - was 15th in 2015-2016 and 18th in 2019-2020, in 2012-2013 ranked 33rd, and in 2007-2009 - only the 52nd.

From class $\mathrm{E}$ in the TOP-20 drugs according to INN there were 8 drugs, from class $\mathrm{N}-$ 8 drugs, which is explained by the presence of concomitant diseases (chronic pancreatitis, gastric ulcer) in patients with LC, for the treatment of which drugs were also prescribed.

Comparison of the results of real clinical practice with the Ukrainian protocol showed the lack of an effective formulaic approach to prescribing drugs to patients in Ukraine, as the list of actually consumed drugs is wider than legally recommended.

\section{Table 2}

TOP-20 drugs (INN) by frequency of prescribing

\begin{tabular}{|c|c|c|c|c|c|c|c|c|c|c|c|c|c|}
\hline \multirow[b]{2}{*}{ INN } & \multirow[b]{2}{*}{$\frac{\tilde{E}}{\tilde{\Xi}}$} & \multicolumn{3}{|c|}{ IV, 2019-2020 } & \multicolumn{3}{|c|}{ III, 2015-2016 } & \multicolumn{3}{|c|}{ II, 2012-2013 } & \multicolumn{3}{|c|}{ I, 2007-2009 } \\
\hline & & $\stackrel{0}{:}$ & $\begin{array}{l}\text { \% pa- } \\
\text { tients } \\
\text { who re- } \\
\text { ceived } \\
\text { drugs }\end{array}$ & $\begin{array}{c}\text { \% in } \\
\text { general } \\
\text { set of } \\
\text { prescrib- } \\
\text { ing }\end{array}$ & : & $\begin{array}{l}\text { \% pa- } \\
\text { tients } \\
\text { who re- } \\
\text { ceived } \\
\text { drugs }\end{array}$ & $\begin{array}{c}\% \text { in } \\
\text { general } \\
\text { set of } \\
\text { prescrib- } \\
\text { ing }\end{array}$ & (20) & $\begin{array}{l}\text { \% pa- } \\
\text { tients } \\
\text { who re- } \\
\text { ceived } \\
\text { drugs }\end{array}$ & $\begin{array}{c}\text { o } \% \text { in } \\
\text { general } \\
\text { set of } \\
\text { prescrib- } \\
\text { ing }\end{array}$ & : & $\begin{array}{l}\text { \% pa- } \\
\text { tients } \\
\text { who re- } \\
\text { ceived } \\
\text { drugs }\end{array}$ & $\begin{array}{c}\% \text { in } \\
\text { general } \\
\text { set of } \\
\text { prescrib- } \\
\text { ing }\end{array}$ \\
\hline Ademetionine & $\mathrm{E}$ & 1 & 90.91 & 10.33 & 2 & 69.09 & 6.09 & 4 & 51.32 & 4.88 & 16 & 17.86 & 1.56 \\
\hline Pantoprazole & $\mathrm{N}$ & 2 & 45.45 & 5.17 & 3 & 63.64 & 5.61 & 8 & 33.33 & 3.17 & 34 & 8.93 & 0.78 \\
\hline Spironolactone & $\mathrm{V}$ & 3 & 43.64 & 4.96 & 1 & 76.36 & 6.73 & 2 & 61.38 & 5.83 & 2 & 69.64 & 6.08 \\
\hline Thioctic acid & $\mathrm{E}$ & 4 & 38.18 & 4.34 & 8 & 40.00 & 3.53 & 1 & 71.43 & 6.79 & 1 & 76.79 & 6.71 \\
\hline Ursodeoxycholic acid & $\mathrm{E}$ & 5 & 38.18 & 4.34 & 14 & 20.00 & 1.76 & 13 & 22.22 & 2.11 & 14 & 21.43 & 1.87 \\
\hline Ornithine & $\mathrm{V}$ & 6 & 36.36 & 4.13 & 5 & 58.18 & 5.13 & 12 & 25.93 & 2.46 & - & - & - \\
\hline Asparaginat K-Mg & $\mathrm{N}$ & 7 & 34.55 & 3.93 & 4 & 61.82 & 5.45 & 6 & 46.56 & 4.42 & 4 & 46.43 & 4.06 \\
\hline Pancreatin & $\mathrm{E}$ & 8 & 30.91 & 3.51 & 11 & 32.73 & 2.88 & 3 & 51.85 & 4.93 & 6 & 41.07 & 3.59 \\
\hline Torasemide & $\mathrm{E}$ & 9 & 29.09 & 3.31 & 7 & 43.64 & 3.85 & 22 & 13.23 & 1.26 & 17 & 17.86 & 1.56 \\
\hline Esomeprazole & $\mathrm{N}$ & 10 & 27.27 & 3.10 & - & - & - & 14 & 17.99 & 1.71 & - & - & - \\
\hline Heparhizine & $\mathrm{N}$ & 11 & 20.0 & 2.27 & - & - & - & - & - & - & - & - & - \\
\hline Furosemide & V & 12 & 18.18 & 2.07 & 9 & 40.00 & 3.53 & 9 & 32.80 & 3.12 & 5 & 44.64 & 3.90 \\
\hline Arginine & $\mathrm{E}$ & 13 & 18.18 & 2.07 & 13 & 20.00 & 1.76 & 5 & 47.09 & 4.47 & 3 & 53.57 & 4.68 \\
\hline Menadione & $\mathrm{E}$ & 14 & 18.18 & 2.07 & 12 & 27.27 & 2.40 & 15 & 17.99 & 1.71 & 22 & 14.29 & 1.25 \\
\hline $\begin{array}{l}\text { Aluminum hydro- } \\
\text { xide + magnesium } \\
\text { hydroxide }\end{array}$ & $\mathrm{N}$ & 15 & 14.55 & 1.65 & 18 & 14.55 & 1.28 & 11 & 28.04 & 2.66 & 12 & 25.00 & 2.18 \\
\hline Thiotriazoline & $\mathrm{E}$ & 16 & 14.55 & 1.65 & 19 & 12.73 & 1.12 & 19 & 15.34 & 1.46 & 9 & 30.36 & 2.65 \\
\hline Mebeverine & $\mathrm{N}$ & 17 & 14.55 & 1.65 & 60 & 1.82 & 0.16 & 26 & 10.05 & 0.96 & 23 & 12.50 & 1.09 \\
\hline Albumin & $\mathrm{V}$ & 18 & 12.73 & 1.45 & 15 & 20.00 & 1.76 & 33 & 6.88 & 0.65 & 52 & 3.57 & 0.31 \\
\hline Methylprednisolone & $\mathrm{N}$ & 19 & 12.73 & 1.45 & 30 & 5.45 & 0.48 & 47 & 3.17 & 0.3 & - & - & - \\
\hline Bionorm & $\mathrm{N}$ & 20 & 12.73 & 4.45 & 40 & 3.64 & 0.32 & 77 & 1.06 & 0.10 & - & - & - \\
\hline
\end{tabular}




\section{Discussion}

Tao Guo, Lei Chang, Yusha Xiao, Quanyan Liu [5] support the efficacy and safety of Ademetionine for the treatment of chronic liver disease, but in cholestasis or viral hepatitis it is, in their opinion, less effective. This drug was the leader in real clinical practice appointments in the Ivano-Frankivsk region of Ukraine in 2019-2020 compared to 2007-2008, when it occupied 16 of the top 20 positions (Table 2). H. Lewis, J. G. Stine [6] claim that proton pump inhibitors are quite often prescribed to patients with LC (approximately $40 \%$ of 400 patients). However, they are associated with a higher risk of developing spontaneous bacterial peritonitis with cirrhotic drugs and should be used with caution or avoided altogether. At the same time, in recent years in Ukraine drugs of this group (Pantoprazole) entered the top three drugs, although in 2007-2009 it occupied 34 rating positions (Table 2). Bernardi M., Moore K. P., Wong F., Gines P., Santos J., Planas R., Pardo A., Durandez R., Cabre E. and others [7-9] claim that aldosterone antagonists (Spironolactone) are the basis for the treatment of ascites in the early stages and are most often recommended, and the combination with Furosemide is most appropriate for patients with recurrent ascites; however, Benmassaoud A., Freeman S.C., Roccarina D. and others suggest that such a combination of diuretics may double the development of other liver complications in cirrhosis [10]. Spironlactone is one of the leaders in drug prescriptions in Ukraine (Table 2). Albumin is more effective than other plasma substitutes (dextran-70, polygelin) for the prevention of circulatory dysfunction after paracentesis [7-9], and in combination with Terlipressin used in the treatment of hepatorenal syndrome, drugs are recommended as standard therapy [11-12]. Mittal V. V., Sharma B. C., Sharma P., Sarin S. K. recommend Lactulose as a first-line drug in the treatment of hepatic encephalopathy [13-15], and Ndraha S., Hasan I., Goh E., Stokes C. S. and others believe that intravenous L-ornithine L-aspartate (LOLA) can be used as an alternative or adjunct in patients with ineffective basic therapy [16-18]. The first line of treatment for spontaneous bacterial peritonitis is antibiotics: third-generation cephalosporins (Cefotaxim, Ceftriaxon), alternatives include amoxicillin/clavulanic acid (Amoxicillin+clavulanate) and fluoroquinolones (Ofloxacin, Norfloxacin) [19-21].

Study limitations. The study of approaches to prescribing pharmacotherapy to patients with LC in real clinical practice in Ukraine was limited to 2 health care facilities in Ivano-Frankivsk region.

Prospects for further research. Carrying out a similar study based on medical card appointment sheets of inpatients with liver cirrhosis (K 74), which were observed in health care facilities of other regions of Ukraine, as well as $\mathrm{ABC} / \mathrm{VEN}$-analysis of the cost of drugs consumed to assess the rational distribution of funds for pharmacotherapy.

\section{Conclusions}

1. Mortality from liver diseases in the world remains high (in 2018 it ranked 11th among the causes of death)

2. Assessment of the dynamics of prescribing drugs to patients with LC in Ivano-Frankivsk region of Ukraine by retrospective $\mathrm{ABC}$-frequency analysis revealed a positive trend in the number of prescriptions on average for one patient (11.4 drugs $\rightarrow 10.5$ drugs $\rightarrow 11.3$ drugs $\rightarrow 8.8$ drugs in $2007-2009 \rightarrow 2012-2013 \rightarrow 2015-2016 \rightarrow 2019-2020$, respectively), namely: over the years, doctors have prescribed fewer drugs, which is a positive fact.

3. The leader among ATC-classification groups during all years of research was group A «Drugs that affect the digestive system and metabolism», and their share has increased in recent years $(44.6 \% \rightarrow 46.6 \% \rightarrow 48.1 \% \rightarrow 48.55 \%)$, the share of dietary supplements also increased from $1.65 \%$ to $6.52 \%$, which indicates a complex and lengthy procedure for registration of medicines in Ukraine.

4. Compatible $\mathrm{ABC}$-frequency analysis showed that the leaders in the years of hospital stay were drugs: Sodium chloride, Ademetionine, Pantoprazole, Spironolactone, Thioctic acid, Ornithine, Asparaginate K-Mg, Phhospholipids, Torasemide, Furosemide. Thus, in 2019-2020, the three leading drugs had the form - Ademetionine, Pantoprazole, Spironolactone; in 2015-2016 Spironolactone, Ademetionine, Pantoprazole; in 2012-2013 - Thioctic acid, Spironolactone, Pancreatin; in 2007-2009 - Thioctic acid, Spironolactone, Arginine. Thus, in the leaders among drugs in each time period of the study remained only Spironolactone. 
5. VEN-analysis of real clinical practice in Ukraine showed that only 9-11\% of drugs were included in vital class $\mathrm{V}, 21-26 \%$ of drugs in class $\mathrm{E}, 64-70 \%$ of drugs in class $\mathrm{N}$, which requires further correction.

6 . The list of actually consumed drugs is wider than legally recommended, due to the presence of comorbidities, the severity of the patient's LC (treatment in the last stages of the disease), the lack of a systematic approach to LC treatment based on evidence-based medicine, but there is a positive tendency to wider use of drugs with proven effectiveness in accordance with European recommendations.

\section{Conflict of interests}

The authors declare that they have no conflicts of interest.

\section{References}

[1] Sarin, S. K., Maiwall, R. Global burden Of liver disease: A true burden on health sciences and economies. e-WGN: e-WGN Expert Point of View Articles Collection. Available at: https://www.worldgastroenterology.org/publications/e-wgn/ e-wgn-expert-point-of-view-articles-collection/global-burden-of-liver-disease-a-true-burden-on-health-sciencesand-economies

[2] Sepanlou, S. G., Safiri, S., Bisignano, C., Ikuta, K. S., Merat, S., Saberifiroozi, M. et. al. (2020). The global, regional, and national burden of cirrhosis by cause in 195 countries and territories, 1990-2017: a systematic analysis for the Global Burden of Disease Study 2017. The Lancet Gastroenterology \& Hepatology, 5 (3), 245-266. doi: http://doi.org/10.1016/ s2468-1253(19)30349-8

[3] Liver cirrhosis (15+), age-standardized death rates by country (2018). Global Health Observatory data repository. Available at: http://apps.who.int/gho/data/node.main.A1092\#

[4] World Total Deaths. Available at: https://www.worldlifeexpectancy.com/world-rankings-total-deaths

[5] Guo, T., Chang, L., Xiao, Y., Liu, Q. (2015). S-Adenosyl-L-Methionine for the Treatment of Chronic Liver Disease: A Systematic Review and Meta-Analysis. PLOS ONE, 10 (3), e0122124. doi: http://doi.org/10.1371/journal.pone.0122124

[6] Lewis, J. H., Stine, J. G. (2013). Review article: prescribing medications in patients with cirrhosis - a practical guide. Alimentary Pharmacology \& Therapeutics, 37 (12), 1132-1156. doi: http://doi.org/10.1111/apt.12324

[7] Angeli, P., Bernardi, M., Villanueva, C., Francoz, C., Mookerjee, R. P., Trebicka, J. et. al. (2018). EASL Clinical Practice Guidelines for the management of patients with decompensated cirrhosis. Journal of Hepatology, 69 (2), 406-460. doi: http:// doi.org/10.1016/j.jhep.2018.03.024

[8] Mellinger, J. L., Volk, M. L. (2013). Multidisciplinary Management of Patients With Cirrhosis: A Need for Care Coordination. Clinical Gastroenterology and Hepatology, 11 (3), 217-223. doi: http://doi.org/10.1016/j.cgh.2012.10.040

[9] Nusrat, S., Khan, M. S., Fazili, J., Madhoun, M. F. (2014). Cirrhosis and its complications: Evidence based treatment. World Journal of Gastroenterology, 20 (18), 5442-5460. doi: http://doi.org/10.3748/wjg.v20.i18.5442

[10] Benmassaoud, A., Freeman, S. C., Roccarina, D., Plaz Torres MCorina, Sutton, A. J., Cooper, N. J. et. al. (2019). Treatments for ascites in people with advanced liver disease. Available at: https://www.cochrane.org/CD013123/LIVER_treatments-ascites-people-advanced-liver-disease

[11] Best, L. M., Freeman, S. C., Sutton, A. J., Cooper, N. J., Tng, E.-L., Csenar, M. et. al. (2019). Treatment for hepatorenal syndrome in people with decompensated liver cirrhosis: a network meta-analysis. Cochrane Database of Systematic Reviews. doi: http://doi.org/10.1002/14651858.cd013103.pub2

[12] Martín-Llahí, M., Pépin, M., Guevara, M., Díaz, F., Torre, A., Monescillo, A. et. al. (2008). Terlipressin and Albumin vs Albumin in Patients With Cirrhosis and Hepatorenal Syndrome: A Randomized Study. Gastroenterology, 134 (5), $1352-1359$. doi: http://doi.org/10.1053/j.gastro.2008.02.024

[13] Sharma, P., Sharma, B. C., Agrawal, A., Sarin, S. K. (2012). Primary prophylaxis of overt hepatic encephalopathy in patients with cirrhosis: An open labeled randomized controlled trial of lactulose versus no lactulose. Journal of Gastroenterology and Hepatology, 27 (8), 1329-1335. doi: http://doi.org/10.1111/j.1440-1746.2012.07186.x

[14] Mittal, V. V., Sharma, B. C., Sharma, P., Sarin, S. K. (2011). A randomized controlled trial comparing lactulose, probiotics, and L-ornithine L-aspartate in treatment of minimal hepatic encephalopathy. European Journal of Gastroenterology \& Hepatology, 23 (8), 725-732. doi: http://doi.org/10.1097/meg.0b013e32834696f5

[15] Vilstrup, H., Amodio, P., Bajaj, J., Cordoba, J., Ferenci, P., Mullen, K. D. et. al. (2014). Hepatic encephalopathy in chronic liver disease: 2014 Practice Guideline by the American Association for the Study Of Liver Diseases and the European Association for the Study of the Liver. Hepatology, 60 (2), 715-735. doi: http://doi.org/10.1002/hep.27210 
[16] Gluud, L. L., Dam, G., Borre, M., Les, I., Cordoba, J., Marchesini, G. et. al. (2012). Lactulose, rifaximin or branched chain amino acids for hepatic encephalopathy: what is the evidence? Metabolic Brain Disease, 28 (2), 221-225. doi: http://doi.org/ 10.1007/s11011-012-9372-0

[17] Ndraha, S., Hasan, I., Simadibrata, M. (2011). The effect of L-ornithine L-aspartate and branch chain amino acids on encephalopathy and nutritional status in liver cirrhosis with malnutrition. Acta Med Indones, 43, 18-22.

[18] Goh, E. T., Stokes, C. S., Sidhu, S. S., Vilstrup, H., Gluud, L. L., Morgan, M. Y. (2018). L-ornithine L-aspartate for prevention and treatment of hepatic encephalopathy in people with cirrhosis. Cochrane Database of Systematic Reviews. doi: http://doi. org/10.1002/14651858.cd012410.pub2

[19] Ricart, E., Soriano, G., Novella, M. T., Ortiz, J., Sàbat, M., Kolle, L. et. al. (2000). Amoxicillin-clavulanic acid versus cefotaxime in the therapy of bacterial infections in cirrhotic patients. Journal of Hepatology, 32 (4), 596-602. doi: http://doi.org/ 10.1016/s0168-8278(00)80221-4

[20] Fernández, J., del Arbol, L. R., Gómez, C., Durandez, R., Serradilla, R., Guarner, C. et. al. (2006). Norfloxacin vs Ceftriaxone in the Prophylaxis of Infections in Patients With Advanced Cirrhosis and Hemorrhage. Gastroenterology, 131 (4), $1049-1056$. doi: http://doi.org/10.1053/j.gastro.2006.07.010

[21] Iogna Prat, L., Wilson, P., Freeman, S. C., Sutton, A. J., Cooper, N. J., Roccarina, D. et. al. (2019). Antibiotic treatment for spontaneous bacterial peritonitis in people with decompensated liver cirrhosis: a network meta-analysis. Cochrane Database of Systematic Reviews. doi: http://doi.org/10.1002/14651858.cd013120.pub2 